\title{
Retrospective review of a single case of surgically treated adolescent idiopathic scoliosis over a forty-year period Joseph P O'Brien
}

\author{
Address: National Scoliosis Foundation, 5 Cabot Place, Stoughton, MA 02072, USA \\ Email: Joseph P O'Brien - jpobrien@scoliosis.org \\ from 4th International Conference on Conservative Management of Spinal Deformities \\ Boston, MA, USA. 13-16 May 2007 \\ Published: 12 October 2007 \\ Scoliosis 2007, 2(Suppl I):P9 doi:10.1 I86/I748-7|6I-2-SI-P9
}

This abstract is available from: http://www.scoliosisjournal.com/content/2/SI/P9

(C) 2007 O'Brien; licensee BioMed Central Ltd.

\section{Objective}

To document the results of surgically treated adolescent idiopathic scoliosis (AIS) over a forty-year period.

\section{Study design}

Retrospective adult case report from initial arthrodesis for AIS at age sixteen years, through fifty-six years.

\section{Methods}

Treatment records for one male patient over a forty-year period were obtained and summarized.

\section{Results}

Initial improvement in Cobb angles occurred in response to a two-stage non-instrumented T4-L2 arthrodesis (T4L2), requiring 243 days inpatient treatment and 120 days of outpatient care. The cost exceeded \$100,000 (1966 dollars). At age 28, lumbar curve progression, fractured arthrodesis, and pain resolved with posterior fusion extension and Harrington rod insertion (T10-L4), requiring 14 days inpatient treatment and 150 days of outpatient home care. The cost was $\$ 50,000$ (1978 dollars). Flatback syndrome, spinal stenosis, sciatica, degenerative disc disease and pain resolved with anterior/posterior revision lumbar surgery including rod replacement, L4/L5 discectomy, insertion of duo harms cages, pedicle screw fixation and fusion extension to L5. The procedure required 7 days inpatient treatment and 35 days of outpatient home care. The cost was \$88,000 (1997 dollars).

\section{Conclusion}

Four surgical procedures cost $>\$ 500,000$ in today's dollars and required more than 560 days of school or work absences. The number of inpatient and outpatient home care days has reduced during this period, but the costs have risen. Research to evaluate long term cost/benefits of surgical correction for AIS is needed. 